\title{
As diferentes configurações da função testemunhal na história do jornalismo: um estudo comparativo entre a Revista da Semana e O Cruzeiro
}

\author{
Eliza Bachega Casadei \\ Universidade de São Paulo - elizacasadei@yahoo.com.br \\ Doutoranda em Ciências da Comunicação pela Escola de \\ Comunicações e Artes da Universidade de São Paulo (ECA-USP) \\ e professora dos cursos de Comunicação Social do Complexo Educacional \\ FMU-FIAM-FAAM. É Mestre em Ciências da Comunicação e graduada em \\ Comunicação Social ambos pela Escola de Comunicações e Artes da \\ Universidade de São Paulo (ECA/USP).
}

\begin{abstract}
Resumo
Embora a função testemunhal seja uma característica central da reportagem jornalística, é possível notar que ela nem sempre se articulou da mesma forma no texto de revista ao longo de sua história. O objetivo do presente artigo é estudar as diferentes configurações a partir das quais a reportagem em revista articulou a função testemunhal em seus textos, a partir de um estudo comparado entre a Revista da Semana e $O$ Cruzeiro. Se, na primeira, a função testemunhal está totalmente calçada no repórter (enquanto actante narrativo), é possível observar, em $O$ Cruzeiro, uma divisão da função testemunhal entre o repórter e outras fontes testemunhais.
\end{abstract}

\section{Palavras-chave}

Reportagem; História; Testemunha.

\begin{abstract}
Although the function of witnesses is a central feature of journalistic reporting, we notice that this is not always articulated in the same way in magazine texts throughout its history. The aim of this paper is to study the different settings from which the witness was articulated in magazine's journalistic writings, from a comparative study between Revista da Semana and $O$ Cruzeiro. If, at the first one, the function of witnesses is fully articulated in the reporter (as narrative character), it can be seen that, in the second one, there is a division between the witness reporter and other witness sources.
\end{abstract}

Keywords

Report; History; Witness.

Artigo recebido em 03/05/2012

Aprovado em 28/04/2012 


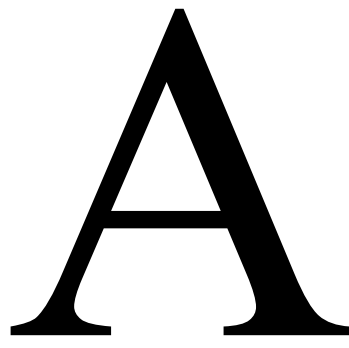

função testemunhal, em sua apropriação pela atividade jornalística, pode ser definida como uma estratégia discursiva da reportagem a partir da qual há uma confirmação da suposta existência de um acontecimento noticiado a partir da evocação a nestes termos, serve tanto como lastro imaginário da autenticidade do acontecimento no nível discursivo, como estratégia de referencialidade e legitimação em torno do narrado. A importância da função testemunhal na reportagem pode ser atestada pelo uso, desde seus primórdios, de fotografias ou ilustrações, entrevistas, bem como técnicas de observação diversas.

Embora a função testemunhal seja uma característica central da reportagem, é possível notar que ela nem sempre se articulou da mesma forma nos textos jornalísticos de revista ao longo de sua história. O objetivo do presente artigo é estudar as diferentes configurações a partir das quais a reportagem em revista articulou a função testemunhal em seus textos, a partir de um estudo comparado entre A Revista da Semana e $O$ Cruzeiro ${ }^{i}$.

\section{O lugar social do testemunho e a atividade jornalística}

As estórias que a imprensa conta, para Mouillaud (2002, p. 117), podem ser comparadas a um "quarto de ecos onde ressoa o concerto de vozes que, sem ele, não teria eco", fazendo remissão, com isso, ao constante sistema de citações a que a imprensa recorre para contar as suas histórias. Uma vez que a função testemunhal não é apenas um dos elementos da produção noticiosa, mas sim, uma de suas matrizes imaginária de verdade presumida, conforme discutiremos a seguir, a própria narrativa noticiosa perderia a sua sustentação e legitimidade enquanto produção simbólica sem esta remissão ao lugar social do testemunho.

É importante ressaltar, contudo, o caráter essencialmente histórico dos modos a partir dos quais a função testemunhal se fez enxergar nas narrativas jornalísticas ao longo de sua existência. Até o final do século XIX, como nos lembra Mouillaud (2002, p. 117), a imprensa em geral funcionava como uma espécie de extensão de um palanque, uma vez que a sua função principal era permitir aos políticos que os seus discursos fossem veiculados para além das tribunas parlamentares. Para este autor, o fim da imprensa tribuna marca não apenas um reposicionamento político e cultural da 
imprensa, mas também uma diversificação de vozes, inaugurando mesmo o tempo da “imprensa-eco (de vozes, que não a sua)".

Para que possamos aprofundar a questão da historicidade dos modos de testemunho jornalístico - e suas rearticulações narrativas no jornalismo de revista - é necessário discutirmos primeiramente por que a função testemunhal pode ser identificada a uma função de verdade imaginária nas narrativas jornalísticas.

Ora, é justamente a funcionalização do testemunho enquanto uma função de verdade que assegura, para muitos autores, as condições necessárias para a constituição dos laços societários. E isso, no sentido de que é apenas na pressuposição de um mundo comum, no sentido de partilhado, que estão instaladas tanto a crítica quanto a confiabilidade no testemunho. Para Ricoeur (2007), por exemplo, o ato de testemunhar tem consistência e sentido apenas porque pressupomos que uma pessoa é capaz de dizer a verdade, ou seja, porque confiamos na capacidade cognitiva do outro e porque acreditamos no comprometimento moral deste que fala. É neste aspecto que está o caráter moral do testemunho e o seu estatuto como um laço de sociabilidade.

Entendido por Ricoeur, portanto, como uma instituição social, o testemunho, para o autor, é o resultado da articulação entre a asserção da realidade e a autonomeação do sujeito que testemunha, conservando em si "a sua confiabilidade presumida" (RICOEUR, 2007, p. 172). É na articulação destes dois momentos que Ricoeur coloca o testemunho como um fator de amparo no conjunto das relações que asseguram os vínculos societários: é a confiabilidade de cada testemunho que assevera a segurança do vínculo social na medida em que ele repousa na confiança na palavra de outrem.

A esta questão, Derrida (1997) acrescenta ainda a problemática de que toda relação comunicacional sempre exige uma fé juramentada posta no testemunho enquanto ato performativo como uma condição necessária de sua inteligibilidade. Como não há resposta sem um princípio de responsabilidade - ou seja, “é preciso responder ao outro, diante do outro e de si próprio" -, esta não pode ser concebida fora de um campo que envolva uma fé jurada ou um juramento, nos termos sempre de uma ação ou, em outras palavras, de um "eu comprometo-me a tanto diante do outro a partir do momento em que me dirijo a ele, ainda que só e talvez, sobretudo, se para cometer perjúrio".

É neste sentido que Derrida define o testemunho como "uma promessa de verdade até mesmo no perjúrio" (DERRIDA, 1997, p. 89). É justamente a crença na possibilidade de manutenção desta promessa de verdade - mesmo na mentira - que assegura o vínculo e laço social. 
Qualquer endereçamento ao outro se tornaria impossível sem a manutenção desta concepção. E é por isso que "no testemunho, a verdade é prometida para além de toda a prova, toda a percepção, toda a mostração intuitiva". E assim,

Ainda que eu minta ou perjure (e sempre e, sobretudo, quando o faço), prometo a verdade e peço ao outro para crer no outro que sou, aí onde sou eu o único a poder testemunhar e onde nunca a ordem da ordem ou da intuição serão redutíveis ou homogêneas a essa fiduciariedade (DERRIDA, 1997, p. 64).

Ao colocar o testemunho sob a ordem de um juramento, Derrida também abre a perspectiva de entendê-lo, tal como o faz Agamben (2011, p. 80), como um vínculo que assegura a própria troca linguageira. A partir do pressuposto de que "o homem é o ser vivo que, para falar, deve dizer 'eu', ou seja, deve 'tomar a palavra', assumi-la e tornála própria”, a língua só pode ser concebida dentro do espaço de um testemunho juramentado, uma vez que só pôde ser produzida

No momento em que o ser vivo, que se encontrou cooriginariamente exposto tanto à possibilidade de verdade quanto à da mentira, se empenhou em responder pelas suas palavras com sua vida, em testemunhar por elas na primeira pessoa (AGAMBEN, 2011, p. 80).

Além de situar o juramento como a base do pacto político do Ocidente, em seu sentido de grande articulador dos laços sociais, nestes termos, Agamben também o aloca como um mecanismo indispensável da antropogênese, como um elemento central que diferencia a linguagem humana de todas as outras formas linguageiras. Isso porque, além do problema da inadequação entre o significante e o significado que, já para LéviStrauss, se constituía como o limite para todo o conhecimento humano, Agamben coloca que:

Além disso e, talvez, mais decisivo para o ser vivo que se descobriu falante, deve ter sido o problema da eficácia e da veridicidade de sua palavra, ou seja, do que poderia garantir o nexo original entre os nomes e as coisas e entre o sujeito que se tornou falante - portanto, capaz de asserir e de prometer - e as suas ações (AGAMBEN, 2011, p. 79).

Ora, o juramento está mesmo na base destas supostas asserções que fazem com que, para além de todo o abismo e inadequação existentes entre o significante e o significado, que jamais se encontram em uma relação de coincidência, haja, não obstante isso, uma esfera de certeza de sentido em torno do nome, em torno do significado de um termo. 
Ao discorrer sobre a certeza que rodeia o nome, Agamben remete ao famoso questionamento de Wittgenstein: "sei que me chamo Ludwig Wittgenstein ou apenas o creio? (...) Se o meu nome não for L.W., como poderei confiar naquilo que se deve entender por verdadeiro ou falso?". Para Agamben, trata-se de um questionamento que mostra que "a segurança que diz respeito à propriedade dos nomes condiciona qualquer outra certeza". E assim,

Se alguém põe em questão, na linguagem, o próprio momento da nomeação sobre o qual se fundamenta todo o jogo linguístico, então se torna impossível falar e julgar. Contudo, Wittgenstein mostra que aqui não se trata de uma certeza do tipo lógico ou empírico, e sim, de algo parecido com uma regra do jogo que é a linguagem (AGAMBEN, 2011, p. 64).

Trata-se de uma certeza que a linguagem traz consigo enquanto promessa, mesmo diante da incapacidade de sua realização.

$\mathrm{Na}$ acepção de Agamben, o que explica essa força presente no juramento - e, portanto, partilhada no testemunho - é a própria força performativa que este assume na linguagem. Ora, uma vez que o performativo pode ser definido como um enunciado que não descreve um estado de coisas, mas sim, realiza imediatamente o fato na sua enunciação, adquirindo, em sua simples pronúncia, a eficácia de um ato, ele só pode se realizar na medida em que efetua a suspensão do caráter denotativo normal da linguagem.

O verbo performativo constrói-se necessariamente com um dictum que, considerado em si, tem natureza puramente denotativa, e sem o qual ele continuaria vazio ou ineficaz ('eu juro' não tem valor se não for seguido - ou precedido - por um dictum que o preenche) (AGAMBEN, 2011, p. 66).

O que é importante notar, contudo, é o fato de que este dictum é revogado no mesmo instante em que ele é precedido por este "eu juro": a sua força denotativa perde importância, na medida em que é a força performativa da promessa que adquire o primeiro plano na sentença. E "assim, o performativo substituiu a relação denotativa entre palavra e coisa por uma relação autorreferencial que, excluindo a primeira, põe a si mesma como o fato decisivo" (AGAMBEN, 2011, p. 66).

Na suspensão da relação denotativa, é o próprio modelo de verdade de um enunciado que é rearticulado a partir do uso do performativo:

O modelo de verdade não é, nesse caso, o da adequação entre as palavras e as coisas, mas sim aquele do performativo, no qual a 
palavra realiza inevitavelmente o seu significado. Assim como, no estado de exceção, a lei suspende a própria aplicação unicamente para fundar, desse modo, a sua vigência, assim também, no performativo, a linguagem suspende a sua denotação precisamente e apenas para fundar seu nexo existentivo com as coisas (AGAMBEN, 2011, p. 66).

A implicação disso está no fato de que, no juramento (e no testemunho) é estabelecida uma distinção entre o próprio juramento e o seu conteúdo semântico. Nestes termos, a relação que ele estabelece com o verdadeiro está no seu aspecto formal, independentemente do conteúdo que serve de objeto a esta fé juramentada.

Enquanto articulação formal, portanto,

O juramento não tem a ver com o enunciado como tal, mas com a garantia de sua eficácia: o que nele está em jogo não é a função semiótica e cognitiva da linguagem como tal, mas sim, a garantia de sua veracidade e da sua realização (AGAMBEN, 2011, p. 12).

E isso porque "individual ou coletivo, o juramento só existe em virtude daquilo que reforça e torna solene: pacto, empenho, declaração". E assim, "ele prepara ou conclui um ato de palavra que só possui um conteúdo significante, mas por si só mesmo não enuncia nada". Mais do que isso, a sua função de verdade "não reside na afirmação que produz, mas na relação que institui entre a palavra pronunciada e a potência invocada" (BENVENISTE apud AGAMBEN, 2011, p. 12).

Se o juramento é um ato verbal que realiza uma garantia independentemente de o fato enunciado acontecer ou não, é porque a sua força performativa reside na forma, independentemente da asserção que o acompanha. Nestes termos, há uma promessa de verdade inserida no testemunho que se instala independentemente do assunto relatado.

Ora, a partir dos autores estudados, é possível entrever que é esta força performativa do juramento - enquanto articulador das relações sociais e do próprio compartilhamento social da linguagem - que está na base do testemunho e que garante o seu modelo de verdade imaginário.

Transportando essa questão para o jornalismo, podemos dizer que o testemunho se configura como uma de suas matrizes de verdade presumida na medida em que não importa necessariamente qual é o assunto que o repórter narra: em todas as reportagens existe sempre uma promessa imaginária de verdade que é garantida pelo estatuto social do testemunho - estatuto este que o jornalismo se apropria em suas construções de sentido. E é disto que advém a estruturação jornalística em torno do testemunho. 
Uma vez isso posto, podemos retomar ao estatuto histórico das formas a partir das quais o testemunho é evocado no jornalismo, por meio de um estudo comparativo entre a Revista da Semana e O Cruzeiro.

\section{O testemunho do repórter na Revista da Semana: monopólio do repórter}

Fundada em 1900 como um encarte do Jornal do Brasil, a Revista da Semana ainda se apresenta como uma revista de passagem, entre o século XIX e o século XX, uma vez que ela ainda está calcada em um modelo em que a reportagem não se constitui como o principal gênero textual em seus domínios. Embora ela já apareça de uma forma bem mais ostensiva nas revistas do século XIX, é possível dizer que a reportagem era apenas um gênero em meio a inúmeros outros textos literários e culturais.

Nas reportagens que ela publicava, contudo, é possível notar que a função testemunhal se apresentava de uma forma bastante específica: ela se estruturava exclusivamente em torno da figura do repórter. Na Revista da Semana, é possível notar um autor que se deixa ver o tempo todo a partir dos códigos padronizados de narração que são articulados nas estórias que conta.

Na edição de 03/11/1945, por exemplo, a Revista da Semana noticiava a triste história do assassinato da Irene Romero Cid de Freitas, cujo corpo, esquartejado, havia sido encontrado dentro de uma mala no Rio de Janeiro. Para contar essa estória, o repórter Celius Aulicus iniciava a sua reportagem contando o trabalho da própria reportagem com os seguintes termos:

Há muitos anos já que os acontecimentos restritos unicamente aos noticiários policiais não nos faziam abalar da redação para o local de um crime ou de uma catástrofe de repercussão nacional. Agora, porém, sob as vistas curiosas de uma multidão de proletários e indigentes, entre os elementos de uma caravana policial, cercados pelos colegas dos jornais diários, eis-nos novamente às voltas com um sensacional caso de morte (REVISTA DA SEMANA, 03/11/1945).

Para além desta referência inicial ao trabalho da imprensa, todo o relato prossegue a partir da adoção do ponto de vista do lugar ocupado pelo repórter e suas impressões. Diferentemente do que estamos acostumados nas reportagens atuais, a essas impressões do repórter não se contrapõem entrevistas com os presentes no local, nem mesmo com o delegado que conduzia as investigações ou com os acusados - toda a 
articulação do relato é dada pela fala do repórter que, no nível textual, se coloca como a principal testemunha e narrador em primeira pessoa. O seu papel enquanto testemunha é reforçado ainda por uma ênfase bastante acentuada dada na descrição do trabalho dos outros profissionais da imprensa que também estavam no local.

A descrição do trabalho de reportagem é mesmo uma estratégia narrativa comumente utilizada nas reportagens da Revista da Semana, a ponto de ser possível encontrar, na edição do dia 12/07/1941, o seguinte subtítulo em uma reportagem sobre cegos que voltam a enxergar: "como nasceu a ideia da reportagem":

\section{COMO NASCEU A IDEIA DA REPORTAGEM}

Numa das sessões plenárias [do Congresso Brasileiro de Oftalmologia] tivemos ocasião de ouvir interessante tese sobre um caso em que quatro irmãos [que voltaram a enxergar]. (...) As surpresas infindáveis que eles poderiam ter tido, tudo isso deveria ser tão interessante que não resistimos ao desejo de aproximarmo-nos do dr. Bandeira Cavalcanti e conversar com ele sobre o caso. Insistimos muito para obter o seu consentimento na publicação de algumas observações que não eram propriamente médicas e a muito custo conseguimos que ele nos autorizasse a falar sobre o caso em nossa revista.

Pouco depois, nos despedimos do dr. Bandeira Cavalcanti, agradecidos pela amável palestra que nos concedera sobre um problema curiosíssimo (REVISTA DA SEMANA, 12/07/1941).

$\mathrm{O}$ estilo de narração utilizado por essa matéria está longe de ser isolado. $\mathrm{Na}$ Revista da Semana é bastante comum encontrarmos, nas reportagens, passagens em que o próprio trabalho da reportagem é enfatizado, com uma proeminência bastante acentuada no papel do repórter, nas suas impressões e nos seus métodos de apuração marca de uma imprensa que adora remeter a si própria, para além do fato noticiado.

Isso mostra, de uma maneira geral, alguns modos a partir dos quais a função testemunhal se articulava nas revistas do início do século XX, engendrando modos de semantização do acontecimento que, em grande medida, foram abandonados (ou, pelo menos, foram bem menos largamente utilizados) no(s) jornalismo(s) posteriores.

"Quando falamos em uma boa prosa", para Wood (2011, p. 47), raramente comentamos que ela "traz em si as marcas do autor, que, embora perceptíveis, paradoxalmente não se deixam ver". A questão é que existem gradações em torno do realce dessas marcas de autor, de forma que, em alguns relatos (mesmo os jornalísticos), há a subversão deste "não deixar-se ver", em favor de determinadas articulações de efeitos de sentido. No jornalismo praticado pela Revista da Semana, o realce das marcas 
do autor leva ao engendramento de uma função testemunhal que está totalmente calçada no repórter.

Não existem outros personagens ou elementos textuais que assumem a função testemunhal (mesmo que a partir da permissão deste narrador) e, desta forma, a figura do repórter (posto mesmo como um dos personagens da narrativa) é mais do que um mero organizador textual e mais do que uma das vozes do relato: ele monopoliza a função testemunhal em torno do narrado.

Nestes textos, o repórter faz questão de explicitar a sua presença, na medida em que é torno do seu testemunho que se articula o modelo de verdade do relato tecido. A partir dos códigos padronizados de narração comumente utilizados, podemos remeter mesmo a um martírio do repórter, na medida em que todo o relato é articulado a partir da figura de linguagem chamada pelos gregos de martyria ( $\mu \alpha \rho \tau v \rho i ́ \alpha)$, que consiste na figura de estilo que "confirma algo pela própria experiência de alguém" (LANHAM, 1991, p. 188).

Nos relatos da Revista da Semana, a figura do repórter funciona como um actante que não apenas organiza o espaço textual, mas sim, que monopoliza a função testemunhal enquanto prova de verdade imaginária. Se, ao longo do século $\mathrm{XX}$, a narrativa jornalística em revista irá eleger outros actantes para cumprir essa função, neste momento, esta é função do personagem-repórter.

Embora o testemunho do repórter continue a exercer um papel essencial enquanto matriz de verdade presumida no jornalismo de revista nos períodos posteriores é patente o modo como outras figuras testemunhantes passam a dividir o espaço com o repórter (não enquanto sujeito empírico, mas sim, em sua posicionalidade como personagem atuante na narrativa), rearticulando, com isso, a própria função testemunhal no jornalismo.

\section{A função testemunhal na revista $O$ Cruzeiro: divisão entre o repórter e as fontes}

No que diz respeito à função testemunhal, é possível observar uma rearticulação bastante acentuada em $O$ Cruzeiro em relação à Revista da Semana. De um lado, é possível observar que cresce, em relação ao período anterior, a importância da voz do repórter. Há mesmo uma supervalorização desta figura na medida em que o repórter se assume enquanto sujeito participante do acontecimento e, sob a perspectiva da 
reportagem enquanto experiência, relata as suas observações de um ponto de vista participante e subjetivo, em uma narrativa que ganha, não raro, ares de diário.

Ao mesmo tempo, contudo, que a voz do repórter ganha maior proeminência, é possível observar também um movimento de contenção na narrativa. E isso no sentido de que, ao contrário do período anterior, o repórter passa a dividir a sua experiência com outros atores participantes do evento. Ele passa a dividir a função testemunhal com outras testemunhas.

Para relatar o seu encontro com Mistinguette, Jean Manzon nos conta, por exemplo, em sua reportagem, que:

No meu terceiro dia em Paris resolvi fazer algumas coisas que nunca fizera antes: visitar os lugares tão falados no estrangeiro e tão desconhecidos dos próprios parisienses. Fui à Torre Eiffel, entrei em Notre Dame, demorei-me no Louvre e, por fim, depois de carregar minha máquina fotográfica, tomei o rumo do apartamento de Mistinguette (O CRUZEIRO, 23/11/1946).

As impressões transbordam em todos os cantos do relato como quando, por exemplo, o fotógrafo coloca que

logo que Mistinguette transpôs a fronteira de sombra e luz que existe em seu luxuosíssimo apartamento, compreendi a grande tragédia dessa incomparável e alegre mulher. Nunca a velhice poderia ser mais dramática, nunca um corpo lutou tanto contra o poder arrasador dos anos (O CRUZEIRO, 23/11/1946).

Na mesma edição, o repórter Edgar Morel relatava, em "O Drama do Açúcar", que "após quatro séculos da fundação do engenho de açúcar, em São Vicente, em São Paulo, passei um dia numa usina deste produto, no interior fluminense" (O CRUZEIRO, 23/11/1946).

Da mesma forma que em a Revista da Semana, estamos diante de um narrador comprometido em um grande número de reportagens de $O$ Cruzeiro. Embora se trate de um narrador necessariamente subjetivo, é necessário enfatizar que ele articula os seus próprios regimes imaginários de verdade, de forma que ele próprio se apresenta como um fiador da função testemunhal e, portanto, como o portador de um voto imaginário de verdade. Há uma espécie de promessa ou de fé juramentada que depositamos neste narrador e que, de uma forma geral, nos leva a crer na veracidade de sua experiência e de seu relato. A promessa de verdade (mesmo no perjúrio) que está pressuposta no estatuto social da função testemunhal e que, por sua vez, é fagocitada pelo jornalismo, é o ponto nodal de articulação do código experiencial em primeira pessoa. Essa promessa 
de verdade até mesmo no perjúrio presente nas articulações socialmente referendadas do testemunho - e articulada sob a forma de um significante que independe do conteúdo que o preenche devido à sua própria força performativa - é o que nos garante o modelo de verdade imaginário presente nos relatos dos repórteres de O Cruzeiro.

Neste aspecto, podemos ver mesmo uma aparente semelhança entre os modelos de verdade imaginária que sustentavam as narrativas de A Revista da Semana e aquele que sustenta as narrativas de $O$ Cruzeiro. Essa aparente semelhança, contudo, se esvazia a partir da análise dos outros códigos de narração que também compunham as narrativas de O Cruzeiro: ao contrário do que acontecia nas primeiras revistas do século $\mathrm{XX}$, em O Cruzeiro, o repórter não atua mais como o actante que monopoliza a função testemunhal enquanto prova de verdade imaginária. Embora o testemunho dele funcione, de fato, como uma das forças motrizes da narrativa, a função testemunhal passa, a partir da década de 1940, a ser dividida com outras testemunhas.

Neste ponto, é necessário demarcarmos uma questão importante. A reportagem jornalística, de fato, nunca pôde se fiar apenas no repórter como fonte de informação. A asserção de que as reportagens da Revista da Semana eram caracterizadas por dispositivos narrativos de semantização a partir dos quais era o repórter quem monopolizava a função testemunhal em torno do narrado não implica na assunção de que outras fontes de informação não participassem da constituição da reportagem ou que o relacionamento entre os repórteres e as fontes não existissem. Significa sim que, no nível da narração, não havia um código padronizado de narração que atuasse no sentido de explicitar e enfatizar essas vozes das fontes no texto.

Sempre atuante em segundo plano, a voz da fonte era um tipo de voz discreta, uma vez que era a própria voz do jornalista que, na narrativa, assumia o primeiro plano do relato. Cabe lembrar, também, que a entrevista era ainda um gênero discursivo muito raro nas revistas e, frequentemente, era possível folhear várias edições sem encontrá-las.

Sobre esse tema, Lodge (2010, p. 130) chama a atenção para o fato de que as narrativas em geral alternam o tempo inteiro entre duas formas possíveis de inserir a fala dos personagens na estória: o mostrar e o dizer. "A forma mais pura de se mostrar são as falas dos personagens, em que a fala espelha com precisão o acontecimento (uma vez que o acontecimento é linguístico)". Já no campo do dizer, a sua forma mais pura diz respeito ao resumo autoral, "em que a concisão e a abstração da linguagem do narrador apagam o caráter particular e individual dos personagens e das suas ações". Dentro desse campo, as vozes das fontes nas narrativas da Revista da Semana estão 
sempre circunscritas a um campo do dizer. Em outros termos, a voz do repórter é fiadora da voz de todas as demais testemunhas nas reportagens da Revista da Semana. Ela funciona como o lastro que assegura o seu valor de valor imaginário.

Ora, a partir da década de 1940, O Cruzeiro passa a adotar novas formas estéticas de materialização da voz da fonte no nível da narrativa da reportagem - um procedimento que, mesmo nesta época, era pouco usado pela Revista da Semana, mostrando a não linearidade na adoção das técnicas narrativas. A circunspecção que rodeava a fonte e a fazia dependente de um repórter que a enunciasse é, no que concerne aos efeitos de sentido articulados no texto, esvaziada. A voz da fonte, finalmente, se autonomiza da voz do repórter, deslocando a dicotomia para o lado do mostrar.

Há, portanto, a autonomização da fonte, enquanto efeito de sentido discursivo, e uma valorização da fonte enquanto voz narrativa.

A questão, portanto, é que a partir da década de 1940, há mesmo uma explicitação muito acentuada da presença e da voz das fontes testemunhais nas narrativas das reportagens de $O$ Cruzeiro, que se autonomizam no texto, sem que a voz do jornalista tenha que falar por elas, servindo-lhes como fiador. Enquanto efeito discursivo é a fonte que, a partir de agora, fala por si própria.

Como exemplo, podemos citar a própria reportagem sobre Mistinguette, onde a fala do repórter é entrecortada pelo próprio depoimento da artista. A inserção da voz de outras testemunhas toma a forma, em O Cruzeiro, de uma hibridização entre a entrevista e a reportagem, na medida em que longos trechos da interação repórter-testemunha são inseridos no meio do texto da matéria. Diferentemente das reportagens estudadas na Revista da Semana, são as fontes que assumem o próprio dito, sem a necessidade de um repórter que funcione como lastro de sua autenticidade.

Isso tem consequências importantes no que se refere à imputação de uma fala. A responsabilidade pelo dito passa a ser atribuída à própria fonte o que implica, de um lado, em uma perda do valor do repórter enquanto fiador da fala e, de outro, à responsabilização deste outro pelo seu próprio dito, livrando o repórter da abonação deste outro quanto ao seu enunciado.

Mais importante do que isso, contudo, se refere ao fato de que é apenas enquanto fala autonomizada que a voz da fonte pode se afirmar enquanto uma voz que atende à função testemunhal.

Tal como definido por Ricoeur (2007, p. 172), o testemunho só pode ser concebido a partir (1) da declaração pela experiência de seu autor - uma vez que se a 
própria narração "não fizer menção à implicação do narrador, limitar-se-ia a uma simples informação" e não a um testemunho, pois a cena narraria a si mesma - e; (2) do acoplamento disso "com a autodesignação do sujeito que testemunha", pois "deste acoplamento [entre a asserção da realidade e o autonomeação de quem faz o testemunho] procede a sua fórmula típica: eu estava lá".

No que diz respeito a este segundo aspecto, é importante enfatizarmos que, em sua definição, é a própria testemunha que se declara enquanto tal. Ela se nomeia enquanto testemunha. Para Ricoeur (2007, p. 172), há "um triplo dêitico que pontua essa autodesignação: a primeira pessoa do singular, o tempo passado do verbo e a menção ao lá em relação ao aqui”".

Ora, enquanto a voz da fonte ainda se apresentava enquanto uma voz acoplada à voz do jornalista, não era possível pensarmos na efetivação deste segundo aspecto da função testemunhal para ela. O lastro fornecido pela voz do jornalista, enquanto actante, para todas as demais fontes de informação do texto eclipsava as possiblidades de autonomeação (enquanto instrumento discursivo mesmo que controlado pelo próprio jornalista empírico) dos demais personagens que participavam da estória, descaracterizando as fontes em seu papel testemunhal.

É neste sentido que podemos dizer que, nas reportagens da Revista da Semana, era o repórter quem monopolizava a função testemunhal, mesmo diante de outras fontes presentes no texto.

Em O Cruzeiro é possível perceber que, efetivamente a voz da fonte passa por este processo de autonomeação. No que se refere às reportagens jornalísticas em revista, portanto, é apenas quando essa voz da fonte é posta em uma esfera distinta e autonomizada da voz do repórter na narrativa (e, portanto, se torna imputável) que ela pode cumprir uma função testemunhal, diferentemente do que era praticado até então.

Nas reportagens de O Cruzeiro, portanto, podemos dizer que a função testemunhal do repórter (enquanto estratégia de referencialidade e função de verdade) passa, efetivamente, a ser partilhada com outros actantes narrativos. Não é mais o repórter que tem os privilégios exclusivos da função testemunhal: a partir deste momento, outras vozes são ouvidas na narrativa e outros atores passam a exercer o testemunho enquanto ato.

A principal problemática trazida pelo testemunho, para Dulong (1998), é justamente o fato de que "a narrativa é factualizada pela presença de seu narrador em relação ao evento reportado". Isso pode ser interpretado no sentido de que é o próprio 
corpo da testemunha que funciona como uma espécie de presentificação do acontecimento em torno do qual ela testemunha, funcionando como garantia imaginária da verdade do relato.

É justamente em torno deste modelo imaginário de verdade que se ancoram as reportagens de $O$ Cruzeiro. Seja através do testemunho do repórter, seja através do confronto com outros pontos de vista, é a função testemunhal que fornece o substrato para o cumprimento imaginário de uma função de verdade no relato.

A partir da inserção da fonte como testemunha, com o uso do código experiencial em terceira pessoa, há o aprofundamento de uma estratégia a partir da qual

o "declarar-se participante" (...) constitui o processo de "factualização", enquanto estratégia que identifica o relato jornalístico a um mundo de acontecimentos preexistentes à imprensa, ao expor fontes-testemunhas cuja "corporalidade do discurso cria uma ponte com o acontecimento" (GRILLO, 2004, p. 110).

A confiabilidade do relato, sob esta perspectiva, se desloca da corporalidade do repórter e passa a ser dividida com outras testemunhas que também passam a servir como lastro de veracidade em torno do narrado.

\section{Considerações finais}

A comparação entre reportagens publicadas pela Revista da Semana e pelo $O$ Cruzeiro mostra como, embora a função testemunhal sempre tenha sido ao longo da história do jornalismo fundamental para a sua constituição servindo-lhe mesmo como lastro de veracidade, essa função nem sempre se articulou da mesma forma nos textos. Se, na Revista da Semana, é possível observar que a função testemunhal é monopólio do repórter enquanto actante narrativo, em $O$ Cruzeiro ele passará a dividir essa função com outros actantes narrativos ligados a fontes testemunhais mais diversificadas.

Mesmo essa equação, contudo, sofrerá modificações no período posterior. Ao longo da década de 1960, é possível observar uma descaracterização progressiva do estilo narrativo que havia marcado a revista O Cruzeiro desde a década de 1940.

A queda da importância da experiência do repórter é acompanhada, nos dez últimos anos de $O$ Cruzeiro, de uma diversificação de personagens na narrativa que, muitas vezes, deixavam o âmbito testemunhal e não estavam ligadas diretamente ao evento noticiado (como a inserção da fala de especialistas, personalidades e opiniões 
colhidas na rua). Além disso, há também a adoção de outras provas imaginárias de verdade no discurso, como estatísticas, vozes de especialistas e dados científicos.

Embora a revista dure ainda até 1975, podemos notar que, de uma maneira geral, há uma nova rearticulação, desde o início da década de 1960, da função testemunhal enquanto valor de verdade no jornalismo de revista.

A terceira fase da história da narrativa da reportagem em revista no século XX, que começa a florescer em meados dos anos 60, no Brasil, parece ter tomado consciência do fato de que um narrador em primeira pessoa é, necessariamente, um narrador pouco confiável, uma vez que participa da própria história que conta. Ou, mais provavelmente do que isso, talvez tenha se dado conta do reverso desta questão, atentando-se para o fato de que um narrador onisciente não confiável é, necessariamente, uma impossibilidade lógica.

A voz intrusiva do autor, finalmente, sai de moda no jornalismo de revista nesta época, não tanto porque essa voz atrapalha o efeito de real em torno do narrado - as reportagens dos períodos anteriores tinham os seus próprios modos de articular esses artifícios de realidade, bem como os seus próprios regimes de real -, mas sim, porque uma outra partilha do sensível começa a entrar em operação.

A partir da sofisticação das provas imaginárias de verdade que emergem na narrativa jornalística a partir dos anos 60 , uma nova configuração narrativa toma corpo.

A função do testemunho enquanto função de verdade, nesta perspectiva, se esvanece da narrativa jornalística. Como aponta Derrida (2005), quando o testemunho aparece confirmado e se transforma em uma verdade teórica demonstrável devido ao seu cotejo com outros dados que validam o dito, o próprio testemunho corre o risco de perder o seu valor e o seu sentido. As provas externas ao testemunho, assim, embora acrescentem um ancoramento imaginário e uma série de efeitos de real, tem como custo a inserção do testemunho em um campo paradoxal que atinge a sua própria constituição: quando confirmado, um testemunho já não é confirmado enquanto testemunho.

Nesta perspectiva, a confirmação do testemunho pelas provas externas não fazem mais do que forçar este testemunho a se tornar uma outra coisa, uma vez que ele foi despojado da promessa de verdade (mesmo no perjúrio) que o sustenta.

O que distingue o testemunho do conhecimento, para Derrida, é, justamente, o fato de que não existe testemunho sem juramento ou sem uma fé juramentada que marca a relação daquele que testemunha com os outros. 
Uma vez que "ninguém pode testemunhar no lugar de outro, assim como ninguém pode morrer no lugar de outro, e é nisso que vemos a aliança da morte e do segredo" (DERRIDA, 2005, p. 82), uma narrativa testemunhal será sempre uma área assombrada pela possibilidade da dúvida e, nas mudanças sofridas pela narrativa jornalística a partir da década de 1960, é justamente a contenção deste estatuto que vemos enunciada.

\section{Referências Bibliográficas}

AGAMBEN, Giorgio. O Sacramento da Linguagem. Belo Horizonte: UFMG, 2011.

DERRIDA, Jacques. "Fé e Saber: as duas fontes da 'religião' nos limites da simples razão". In DERRIDA, Jacques e VATTIMO, Gianni (dir.). A Religião: seminário de Capri. Lisboa: Relógio D’Água, 1997.

DERRIDA, Jacques. Sovereignties in Question: the poetics of Paul Celan. New York: Fordham University Press, 2005.

DULONG, Renaud. Le Témoin Oculaire. Paris: EHESS, 1998.

GRILlO, Sheila Vieira de Camargo. A produção do real em gêneros do jornal impresso. São Paulo: Humanitas, 2004.

LANHAM, Richard A. A Handlist of Rhetorical Terms. Berkeley: UCP, 1991.

LODGE, David. A Arte da Ficção. Porto Alegre: LP\&M, 2010.

MOUILLAUD, Maurice e PORTO, Sérgio. O jornal: da forma ao sentido. Brasília: Editora UNB, 2002. RICOEUR, Paul. A Memória, a História, o Esquecimento. Campinas: Editora da Unicamp, 2007. 


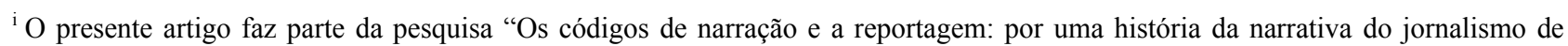
revista no século XX”, desenvolvida na Escola de Comunicações e Artes da Universidade de São Paulo (ECA-USP), que busca mapear as mudanças em termos de estruturação narrativa que as reportagens em revista sofreram ao longo do século XX. O material utilizado foi coletado junto ao acervo do Arquivo do Estado de São Paulo.

Este artigo e todo o conteúdo da Estudos em Jornalismo e Mídia estão disponíveis em http://www.periodicos.ufsc.br/index.php/jornalismo/index

Estudos em Jornalismo e Mídia está sob a Licença Creative Commons. 